\title{
Sensory mechanotransduction at membrane-matrix interfaces
}

\author{
Kate Poole • Mirko Moroni • Gary R. Lewin
}

Received: 27 May 2014 / Revised: 19 June 2014 / Accepted: 20 June 2014 / Published online: 2 July 2014

(C) The Author(s) 2014. This article is published with open access at Springerlink.com

\begin{abstract}
Sensory cells specialized to detect extremely small mechanical changes are common to the auditory and somatosensory systems. It is widely accepted that mechanosensitive channels form the core of the mechanoelectrical transduction in hair cells as well as the somatic sensory neurons that underlie the sense of touch and mechanical pain. Here, we will review how the activation of such channels can be measured in a meaningful physiological context. In particular, we will discuss the idea that mechanosensitive channels normally occur in transmembrane complexes that are anchored to extracellular matrix components (ECM) both in vitro and in vivo. One component of such complexes in sensory neurons is the integral membrane scaffold protein STOML3 which is a robust physiological regulator of native mechanosensitive currents. In order to better characterize such channels in transmembrane complexes, we developed a new electrophysiological method that enables the quantification of mechanosensitive current amplitude and kinetics when activated by a defined matrix movement in cultured cells. The results of such studies strongly support the idea that ion channels in transmembrane complexes are highly tuned to detect movement of the cell membrane in relation to the ECM.
\end{abstract}

Keywords Mechanotransduction · Touch · Ion channels · Extracellular matrix $\cdot$ STOML3 $\cdot$ Laminin-332

\section{Introduction}

The ability of cells to rapidly transform mechanical deflection or changes in applied force into an electrical signal is a

K. Poole $\cdot$ M. Moroni $\cdot$ G. R. Lewin $(\square)$

Department of Neuroscience, Max-Delbrück Center for Molecular

Medicine, Robert-Rössle Straße 10, D-13092 Berlin, Germany

e-mail: glewin@mdc-berlin.de property that is still poorly understood at the molecular level. It is probable that almost all cells sense and respond to mechanical changes in their vicinity. In this review, we will concentrate on fast mechanotransduction, a process by which many cells, especially sensory cells, rapidly transform mechanical stimuli into graded electrical signals. This process is often called mechanoelectrical transduction (MET) and likely requires that a mechanical stimulus directly gates an ion channel. Fast mechanotransduction entails the transformation of mechanical energy into an electrical signal in a sub-millisecond time frame. The gating of ion channels by mechanical stimuli has been studied for many years, and the molecular identity of the first truly stretch-sensitive ion channel was first identified in bacteria in the early 90 s by Kung and his colleagues. This bacterial channel called mechanosensitive channel of large conductance (MscL) can be gated directly by membrane stretch without the need for any accessory proteins [93].

Elegant biophysical work over the last few decades has shown that the detection of sound waves by hair cells of the inner ear is an exquisitely sensitive process in which MET is critically dependent on the placement and mechanical coupling of the transduction channels [8,37]. Thus, functional MET channels are placed at the tips of the hair cell stereocilia and require an intact tip-link connector between stereocilia in order to gate in response to bundle displacements of a few tens of nanometers [3,34]. The molecular composition of the tip link is probably a combination of cadherin-23 and protocadherin-15 dimers which span the 150-200-nm distance between stereocilia tips [55, 90, 91]. Importantly, the presence of cadherin- 23 or protocadherin- 15 or intact tip links appear to be absolute requirements for hair cell mechanotransduction [3,99]. In another well-studied example of a mechanoreceptor, the body touch neurons of the nematode Caenorhabditis elegans and the genetic and electrophysiological studies have definitively demonstrated that the Deg/ $\mathrm{ENaC}$ family members MEC-4 and MEC-10 form the core of 
a mechanosensitive complex in these neurons [2, 33, 82, 83]. However, as for the hair cell, there appears to be a requirement for the presence of extracellular matrix molecules at least for the assembly of a sensitive mechanoreceptor response [32, 82]. The vertebrate hair cell and body touch receptor neurons from $C$. elegans both appear to be examples in which the mechanotransduction channel functions in the context of its associated proteins, including extracellular proteins.

The above examples serve to highlight an apparent dichotomy in which some mechanosensitive channels are directly gated by membrane stretch, and others have only been shown to be mechanosensitive in the presence of other proteins that may be necessary to couple mechanical energy to the ion channels in the membrane (see below). The detection of membrane stretch is undoubtedly an important function of mechanosensing ion channels. However, here, we will argue and provide evidence for the view that in many cases, physiologically relevant fast mechanotransduction, is mediated by transmembrane complexes localized to plasma membranematrix interfaces.

\section{The somatic mechanosensory system}

One important system in which mechanotransduction occurs at membrane-matrix interfaces is the somatic sensory system. The largest and most diverse mechanosensing system of the vertebrate body is elaborated by somatic sensory neurons of the trigeminal and dorsal root ganglia. Almost all the organs of the body are innervated by one or more of these ganglia, and many, if not most, of these sensory neurons are responsive to mechanical stimuli. In a marked contrast to non-neuronal mechanosensory cells of the inner ear, these sensory neurons typically have an extremely long axon extending to the peripheral organ where branches are elaborated, forming endings that detect mechanical stimuli $[64,65]$. It is important to realize that in all cases, the only compartments of the sensory neuron responsive to mechanical stimuli in vivo are the terminal branched endings. This can easily be demonstrated in vivo as mechanical stimulation of the nerve, ganglion or spinal cord does not initiate action potentials in sensory neurons [56]. However, if a peripheral nerve is cut or ligated, many axons acquire mechanosensitivity at the ligation site with a time course consistent with fast anterograde transport [56]. The strict localization of mechanosensitivity to the peripheral endings of sensory neurons suggests that there exist active mechanisms to accumulate, sequester and functionalize transduction molecules at the peripheral endings of the neuron. Indeed, we have previously provided evidence that specialized vesicle pools, called transducosomes, may be used to deliver transduction proteins to peripheral endings [61]. The morphology of sensory endings is complex, but can be divided into those neurons that form endings at specialized end organs like hair follicle afferents [64, 66, 67, 95], Merkel cell neurite complexes [50, 71, 97], Pacinian corpuscles [68, 95], Meissner' corpuscles [45] and muscle spindles [4, 53], and those with so-called free nerve endings $[57,58]$. The latter endings most often belong to sensory endings with nociceptive or thermoreceptive function. Nevertheless, sensory axons with free nerve endings are very often mechanosensitive, but only respond to higher-threshold mechanical stimuli. Morphological and ultrastructural studies have directly demonstrated that the sensory endings within specialized end organs are intimately connected to support cells within their end organ, be they terminal Schwann cells [66] or other cell types like Merkel cells [78, 79].

In the case of sensory afferents with free nerve endings, it is much harder to be sure where the likely sites of mechanosensory transduction reside within the terminal branches. However, even in this case, ultrastructural studies have demonstrated the existence of contacts between the membranes of the nociceptor axons and surrounding cells like keratinocytes [47, 57]. Thus, it is clear that in vivo mechanotransduction by sensory afferents takes place in the context of branched tubular endings that are in contact with neighbouring cells and may have proteinaceous connections with matrix within the end organ $[42,66]$. The relevance of such cellular arrangements for the efficient and fast transduction of small mechanical stimuli relevant for touch perception will be discussed in this review. In particular, we will discuss the appropriateness of available methodologies for the direct recording of mechanoelectric transduction events for in vivo mechanotransduction.

\section{Methods for measuring the activity of mechanosensitive ion channels}

The advent of the patch-clamp technique provided almost unlimited opportunities to directly measure the gating of ionic currents [88]. Thus, the ligand and voltage dependence of ion channel gating can easily be measured either in excised patches or in whole cells. Voltage can be controlled with extremely high precision using the classical voltage clamp paradigm, and thus, there is little ambiguity in determining the voltage dependence of ion channel gating. Similarly, ultrafast methods for applying ligands to patches have allowed precise measurement of the kinetics with which ligand binding favours ion channel gating. In both cases, the precise control of the stimulation parameters is crucial for studying channel gating.

Patch-clamp methods have also been used to study how membrane stretch influences the gating of ion channels. Thus, mechanosensitive membrane currents were described soon after the invention of the patch-clamp technique. Initial studies in chick myotubes [41], Xenopus oocytes [76] and bacteria [5, 
$23,72]$ revealed the presence of endogenous currents sensitive to the application of pressure to the membrane patch. These first experiments were conducted by establishing a seal between the recording pipette and the cell membrane, pressure was then applied directly to the solution in the recording pipette using a microprocessor-controlled piston connected to the electrode holder. This configuration allows the application of pressure exerted through the capillary walls to the membrane under the pipette [59]. The first systems had major drawbacks as they resulted in an uncertainty in the onset of the pressure pulse and a slow rising phase of the pulse itself, which precluded the analysis of the activation kinetics of channels with fast on and off kinetics [43, 74]. The technique was improved by Sachs and collaborators by the introduction of a piezoelectric bending element to control both pressure and vacuum, thus enabling the application of either positive or negative pressure to membrane patches [7]. This technical improvement increased the reliability and reproducibility of measurements of the kinetic properties of mechanically gated ion channels. Almost square wave steps of pressure can today be applied to membrane patches, and channel activity can be recorded in response to a pressure "jump", similar to what was first established for ligand-gated ion channels [17, 35]. However, fast perfusion systems driven by piezo elements offer the possibility of solution exchange in the range of few hundred microseconds, pressure jumps with a high-speed pressure clamp are still limited by a slow rise and decay time in the range of a few milliseconds especially at high pressure values [7], thus precluding an accurate measure of the rise time of mechanically gated currents in sensory cells, which can activate with time constants of much less than $1 \mathrm{~ms}$ [14, 47, 48, 62].

The application of pressure steps via the patch pipette has allowed workers to study the properties of many mechanically gated currents in a variety of cultured cells. Pressure steps can be applied to patches in the cell-attached configuration where channels in the patch are presumably gated in an environment which still contains cortical cytoskeleton and where cytoplasmic factors can still influence gating. Uhtaek $\mathrm{Oh}$ and his colleagues successfully used this method to identify several distinct mechanosensitive currents in the membranes of cultured adult sensory neurons $[15,16]$. Pressure steps can also be applied to excised patches containing channels either in "outside-out" or "inside-out" configurations; in some cases, the membrane bleb may still contain protein material from the cytoskeleton [87, 92]. However, in this latter case, the channel activity is measured in a context lacking mechanical elements linked to the cell cytoskeleton. The following considerations should be taken into account when characterizing mechanically gated channels using pressure jumps. First, since the pressure is applied via the patch pipette, the membrane exposed to the pressure step will typically only be a few square micrometres. Second, most such measurements have been made in cultured cells, and the nature of this technique requires that the recordings are made from patches of membrane acquired from the top of the cultured cell. Thus, access to channels that may be exclusively or predominantly present at membranes immediately adjacent to the cell culture substrate will be difficult, if not impossible, with such an approach. Of course, there are instances where a specialized area of membrane on the surface of cells rich in ion channels can be examined with such an approach. Thus, in the case of hair cells, the stereocilia bundle transduction channels are localized to the tips of just certain rows of stereocilia [8]. It has long been speculated that the cilia of endothelial cells may represent specialized mechanosensitive organelles that detect flow or shear stress as fluids flow across the cell, e.g. in a kidney tubular compartment $[1,54,80]$. Recently, directed patch recordings from membrane compartments containing cilia showed directly that these are enriched for mechanosensitive ion channels [22].

In order to overcome the low density of channels in many cell types, the "outside-out" or "macropatch" configuration has advantages, as the surface of membrane pulled from the cell is considerably larger than the one under the pipette in cell-attached configuration. However, in excised patches, not only are soluble cytoplasmic components lost, but more importantly, mechanically gated channels lose their connection to cytoplasmic proteins which could act as tethers or membrane scaffolds that are functional components of the MET complex. Using pressure steps applied in the on-cell or excised patch configuration, the pressure jump serves to stretch and simultaneously thin the plasma membrane being monitored electrophysiologically. Indeed, functional and X-ray crystallographic approaches have demonstrated that prokaryotic mechanosensitive channels are gated as the membrane thins; thus, membrane stretch leads to a pronounced tilting of alpha helixes within the channel that allows the pore to form [84]. Eukaryotic two-pore domain $\mathrm{K}^{+}$channels (K2P) have long been known to be exquisitely sensitive to membrane stretch when measured in mammalian cells $[13,46,69,70]$. Indeed, biophysical experiments indicated that the gating of these channels is modulated by the shape of lipids in the membrane. They activate in a range of 10 to $30 \mathrm{mmHg}$, and their gating is modulated by fatty acids such as arachidonic acid and membrane crenators [70]. Recently, two of the mammalian K2P channels, TREK1 and TRAAK, were shown by Mackinnon and colleagues to be directly gated by membrane stretch, positive and negative, after reconstitution into lipid bilayers without associated proteins [10]. However, another research group using a similar approach found that TREK1 was intrinsically mechanosensitive in lipid membranes, but was actually closed by the application of positive pressure [6]. It is not yet clear why these two research groups should find fundamentally different modes of mechanosensitivity for the same channel reconstituted in lipid membranes. The mammalian TRAAK and TREK channels are polymodal in nature in 
that they can be gated by temperature as well as membrane stretch. These channels are expressed in sensory neurons where they may be involved in setting the background $\mathrm{K}^{+}$ leak conductance that governs the resting membrane potential. Gene deletion studies have shown that these channels do regulate the excitability of mouse sensory neurons to natural stimuli like temperature and pressure [81]; however, it is unclear to what extent the specific mechanosensitivity of the $\mathrm{K} 2 \mathrm{P}$ channel is responsible for such in vivo phenotypes. The prokaryotic MscL and MscS channels both exhibit dramatic lipid-induced conformational changes associated with gating $[23,93]$. In patch-clamp experiments, MscL is activated at membrane tensions that are close to the lytic limit of the cell [93]; however, MscS is activated by lower tensions similar to those described for the gating of eukaryotic channels like TREK1 and TRAAK [10]. Thus, channel proteins directly gated by membrane stretch can have intrinsic molecular features that regulate their sensitivity to membrane tension.

Recently, two founding members, Piezo1 and Piezo2, of a new mechanosensitive channel family were discovered [19]. These two proteins are extremely large with more than 30 predicted membrane spanning segments, and they are apparently not related to any known ion channel family. Initially, Piezo1-dependent non-selective cation currents were found in neuroblastoma cells using cell indentation as a stimulus. Experiments using excised patches with pressure-clamp stimuli suggested that these channels also sense changes in the lipid bilayer tension $[19,39,40]$. Definitive proof that these proteins do form pore-forming channels was obtained by purifying the mouse Piezol protein and incorporating it into artificial bilayers where channel activity could be measured [20]. Interestingly, no evidence has been presented to date to suggest that purified and reconstituted Piezol channels are directly gated by membrane stretch [20]. The Piezo channels are readily gated by cell indentation and activate relatively rapidly but usually inactivate during steady-state indentation. Cell indentation is, however, a very imprecise and poorly controlled stimulus with which to quantify the kinetics of current activation and inactivation. Pressure-clamp experiments have shown that Piezo1 and Piezo2 both rapidly inactivate under conditions of constant pressure applied to excised patches [39, 40]. The Piezo2 protein has kinetics of activation and inactivation that are reminiscent of a rapidly adapting mechanosensitive current found predominantly in large-diameter dorsal root ganglion neurons [14, 18, 29, 31, 47, 48, 62, $63,75]$, and initial knockdown studies have suggested that this rapidly adapting current is dependent on the presence of Piezo2 [19]. Cell indentation techniques have now been widely used to evoke mechanosensitive currents in sensory cells. Indeed, a non-selective cationic mechanosensitive current with kinetic properties and pharmacology similar to Piezo2 channels has recently been identified in Merkel cells [51, 71, 97]. Genetic ablation of Piezo2 in these cells abolished their mechanosensitivity to an indentation stimulus and attenuated the sustained firing of slowly adapting type I afferents that innervate the Merkel cell [71, 97].

\section{Matrix interactions relevant for fast mechanotransduction in sensory neurons}

In contrast to studies on the sensory hair cell, it has so far proved impossible to make direct high-resolution intracellular recordings from mammalian afferent endings near the site of mechanosensory transduction. The most direct electrophysiological recordings in vivo were made more than four decades ago from Pacinian corpuscle afferents or muscle spindle endings in the cat. This was possible because these mechanoreceptor axons are, in the cat, exceptionally large (circa $50 \mu \mathrm{m}$ in diameter) which allowed the experimenters to make low noise DC recordings of the receptor potential when the end organ was bathed in drugs, like lidocaine, that block action potential initiation [53, 68]. In 1996, Cesare and McNaughton showed that acutely cultured sensory neurons possess a heat-gated cation conductance, which they termed $I_{\text {heat }}$, that exhibits a threshold and response function matching that of heat-sensitive nociceptors [12]. Several groups looked for mechanosensitive currents in acutely cultured sensory neurons that might correspond to a native receptor current activated by physiologically relevant mechanical stimuli. In 1997, Cunningham and colleagues demonstrated that fluid jet stimulation of the neurites of putative aortic baroreceptor neurons could evoke inward currents measured with the whole-cell patch-clamp technique [21]. Later, several groups used direct mechanical stimulation of the cell body or neurites of a cultured rodent's dorsal root ganglion neurons to show that rapidly activating mechanically gated currents can be readily measured in these cells $[18,31,48,75]$. It is now generally agreed that the direct poking of the cell body can evoke both rapidly inactivating and slowly inactivating currents in the majority of cultured dorsal root ganglion (DRG) neurons. There is still, however, a lack of consensus on the basic properties of these currents, as measurements of threshold, activation time constants, inactivation time constants, ionic selectivity and pharmacological sensitivity can vary significantly between laboratories. Some of these discrepancies may be due to methodological issues stemming from variations in the way that mechanical stimuli are delivered to the cell. For example, labs using a classical piezo-driven motor to stimulate cultured neurons report surprisingly large indentations (often $>5 \mu \mathrm{m}$ ) needed to evoke mechanosensitive currents, whereas labs using the Kleindiek nanomotor device to stimulate neurites or cells have seen currents evoked with much smaller stimuli (often $<1 \mu \mathrm{m}$ ). It is likely that the mode of mechanical stimulation will be very difficult to standardize as this method is intrinsically inaccurate due to several factors, discussed in 
more detail below. One major factor is the fact that it is impossible to accurately determine the absolute magnitude of the stimulus when indenting the cell. Usually, a rounded polished glass micropipette is used to indent the cell, but the starting point for the stimulus is necessary at some unknown distance from the neuronal membrane. For example, if a stimulus of $1 \mu \mathrm{m}$ is given and this leads to current activation, the experimenter can only guess that the starting point for the stimulation was a value between 0 and $1 \mu \mathrm{m}$. All groups who have examined mechanosensitive currents in cultured DRG neurons observe a diversity of mechanosensitive currents with different inactivation time constants $(\tau)$. Thus, mechanosensitive currents have been classified as rapidly adapting (RA, $\tau<5 \mathrm{~ms}$ ), intermediately inactivating (IA, $\tau$ 5$50 \mathrm{~ms}$ ) and slowly adapting (SA, $\tau>50 \mathrm{~ms}$ ) [47, 48, 62, 63]. Although there are differences in the details of how groups classify currents according to their inactivation properties, e.g. see Delmas [24], there is broad agreement about the existence of rapidly and slowly inactivating currents. There is also agreement about the finding that RA currents are found in both mechanoreceptors and nociceptors whereas SA currents are found more or less exclusively in nociceptors $[25,30,31,48,62,63]$.

There has been surprisingly little work done on the pharmacology of distinct mechanosensitive currents in sensory neurons. In our hands, using a nanomotor to mechanically stimulate sensory neuron neurites in culture, Ruthenium red was not effective in blocking the RA current, but did reversibly block the SA-type current [48]. Using a piezo-driven motor, Drew and colleagues have recorded RA currents with slightly slower kinetics than those that we have observed and found a reversible block of this current with Ruthenium red. Sensory neuron mechanosensitive currents have been found by two groups to be completely insensitive to block by amiloride and its analogues like benzamil [31, 48]. However, there is one report that amiloride blocks a considerable portion of the mechanosensitive current in both putative mechanoreceptors and nociceptors isolated from rats [18]. Reversibility of the amiloride block was, however, not demonstrated. There is broad agreement that in sensory neurons, slowly inactivating mechanosensitive currents are non-selective cation currents that are susceptible to block by both gadolinium ions and Ruthenium red. However, we have consistently observed very sensitive and fast RA currents that are insensitive to Ruthenium red, reverse at positive potentials and are sodium selective [14, 47, 48, 62, 85]. The mode of mechanical stimulation is undoubtedly important, and it is clear that there is a large variation in the speed of the mechanical indentation used as well as its magnitude; speeds of stimulation vary from 200 to $7,500 \mu \mathrm{m} / \mathrm{s}[18,47]$. The speed is probably a very relevant factor especially considering the fact that the activation of the RA-mechanosensitive current is critically dependent on the stimulus velocity $[44,86]$.
Very fine mechanical stimuli can be delivered to cells or neurites, very rapidly with extremely small step sizes (10 nm or less) using a nanomotor device (Kleindiek, Nanotechnik) [48]. We found that mechanosensitive currents could be evoked more reliably and with smaller stimuli from the newly grown neurites of sensory neurons compared to their cell bodies [48]. This observation suggested that either mechanosensitive channels are enriched in neurite membranes or that they are more readily activated by the mechanical indentation which is in the latter case closer to the culture substrate. We thus hypothesized that the relevant mechanosensitive channels in sensory neurons may be preferentially activated at the membrane-matrix interface of sensory neurons. Indeed, using a combination of electron microscopy, biochemistry and electrophysiology, we were able to demonstrate the presence of a $100-\mathrm{nm}$ long membrane tether at the sensory neuron matrix interface, the presence of which appears to be necessary for RA-current activation. Thus, short-term treatment with specific and non-specific proteases abolished our ability to measure RA-current activation, concurrently with the loss of the 100-nm tether [47]. Twenty four hours after protease treatment, we observed a coincident reappearance of both the tether and the RA-mechanosensitive current. Additionally, cultured sympathetic neurons that lack mechanosensitive currents also lack the tether. The tether protein we observed appears to bind at one end to the laminin-containing matrix, which is most often derived from Engelbreth-Holm-Swarm murine sarcoma cells (EHS-laminin). Interestingly, the subunit composition of the laminin substrate exerts powerful and local control over the presence of mechanosensitive currents and the tether protein. Thus, laminin-332, a trimeric molecule composed of the $\alpha 3, \beta 3$ and $\gamma 2$ laminin chains [28], which is present at the dermalepidermal border of the skin, was found not to support RA currents in cultured primary sensory neurons [14]. It is known that EHS-laminin contains laminin-111 $(\alpha 1, \beta 1$ and $\gamma 1$ chains [52]), but EHS-laminin does not support RAmechanosensitive currents when even small amounts of laminin-332 are present (a ratio of 15:1 of EHS-laminin to laminin-332 is sufficient). Thus, laminin-332 is profoundly inhibitory for the RA-mechanosensitive current, and we could show that this effect was contact-dependent and highly local in nature (Fig. 1). To demonstrate the localized nature of laminin-332-mediated inhibition of mechanosensitive currents, we used microcontact printing to prepare substrates where stripes of EHS-laminin (permissive for mechanotransduction channel gating) and stripes of EHSlaminin/laminin-332, 15:1 (non-permissive), were stamped onto a glass substrate in a cross-hatched pattern. Sensory neurons cultured on these patterned substrates extend neurites along laminin stripes, and we applied localized mechanical stimuli to neurite segments from the same neuron growing on laminin that is permissive or non-permissive for 
a

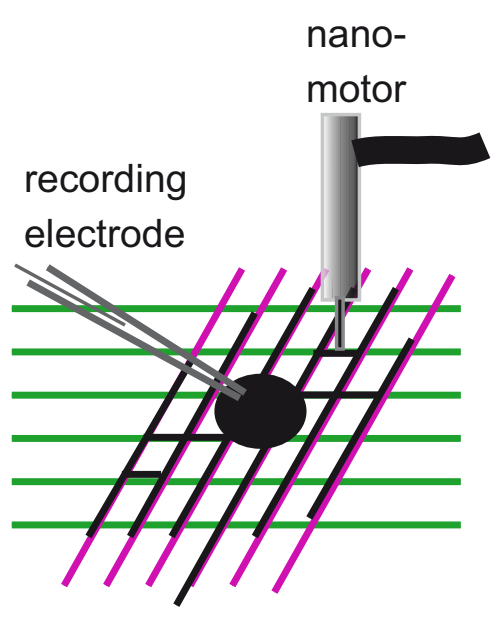

b

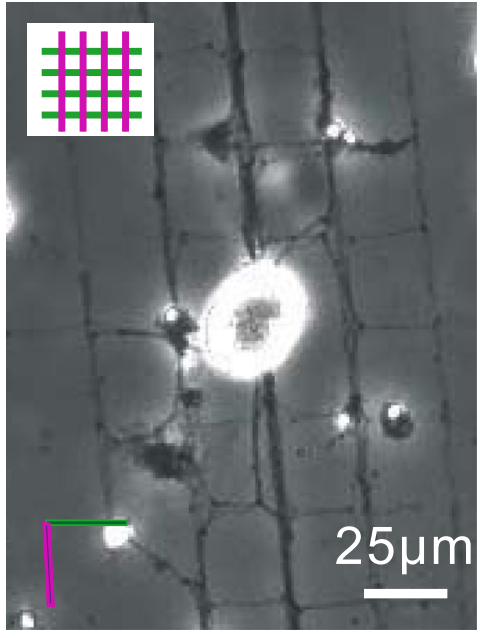

C

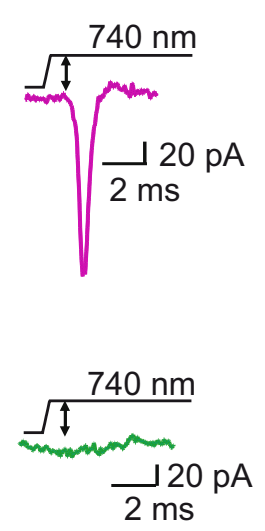

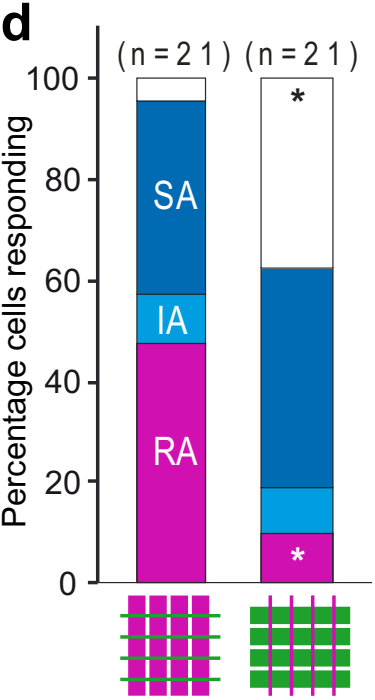

Fig. 1 Local inhibition of mechanically gated currents by laminin-332. a Schema of experimental setup to test the local effects of substrate composition on mechanically gated currents. Somatosensory neurons were acutely prepared from mice and cultured on cross-hatched patterns of laminins created using microcontact printing; magenta indicates EHSlaminin and green EHS-laminin/laminin-332, 15:1. Cells were monitored using whole-cell patch clamp, and a nanomotor was used to indent neurite segments of the same cell over the different substrates. b When sensory neurons are cultured on such patterns, neurites grow exclusively over the printed regions. $\mathbf{c}$ Representative current traces of the cellular response when a cell is probed over the EHS-laminin substrate (magenta trace) vs over the EHS-laminin/laminin-332, 15:1 substrate (green trace). d In matched measurements, the rapidly adapting (RA) current measured in a neurite segment over EHS-laminin was not observed in a significant number of cells when the same cell was stimulated at a neurite segment attached to the EHS-laminin/laminin-332, 15:1 substrate (Student's $t$ test, $* p<0.05)$. Data from [14]

It is thus clear that the cell-matrix interface is critically important for the mechanosensitive currents that we are able to activate by cell body or neurite indentation in sensory neurons. Indentation techniques cannot directly activate mechanosensitive channels present in transmembrane complexes at the plasma membrane-matrix interface. In addition, the precise stimulus resulting from the indentation of the cell soma or a neurite segment with a glass probe is unknown as the size of the probe may vary from experiment to experiment, the precise moment when the probe contacts the surface of the cell is not known and the curvature and elasticity (both variable) of the impact site will modulate the stimulus as it is propagated by the cell itself to the membrane-matrix interface. We set out to design a completely new experimental approach that enables us to apply a mechanical stimulus of known magnitude directly to defined regions of the membrane-matrix interface whilst monitoring the cellular response using wholecell patch clamp (Figs. 2 and 3). Briefly, an elastomeric pillar array was cast from a microfabricated master, with defined dimensions and material properties. To study mechanotransduction in sensory neurons, the tops of the cylindrical elements (pili) within this array are coated with laminin to promote cellular attachment and to restrict neurite outgrowth to the defined circular area. An individual pilus to which a neurite is bound can then be deflected using a nanomotor-driven stimulator, resulting in a mechanical stimulus directly at the cell-matrix interface. By applying pillar deflections with magnitudes between 10 and $1,000 \mathrm{~nm}$ to the 

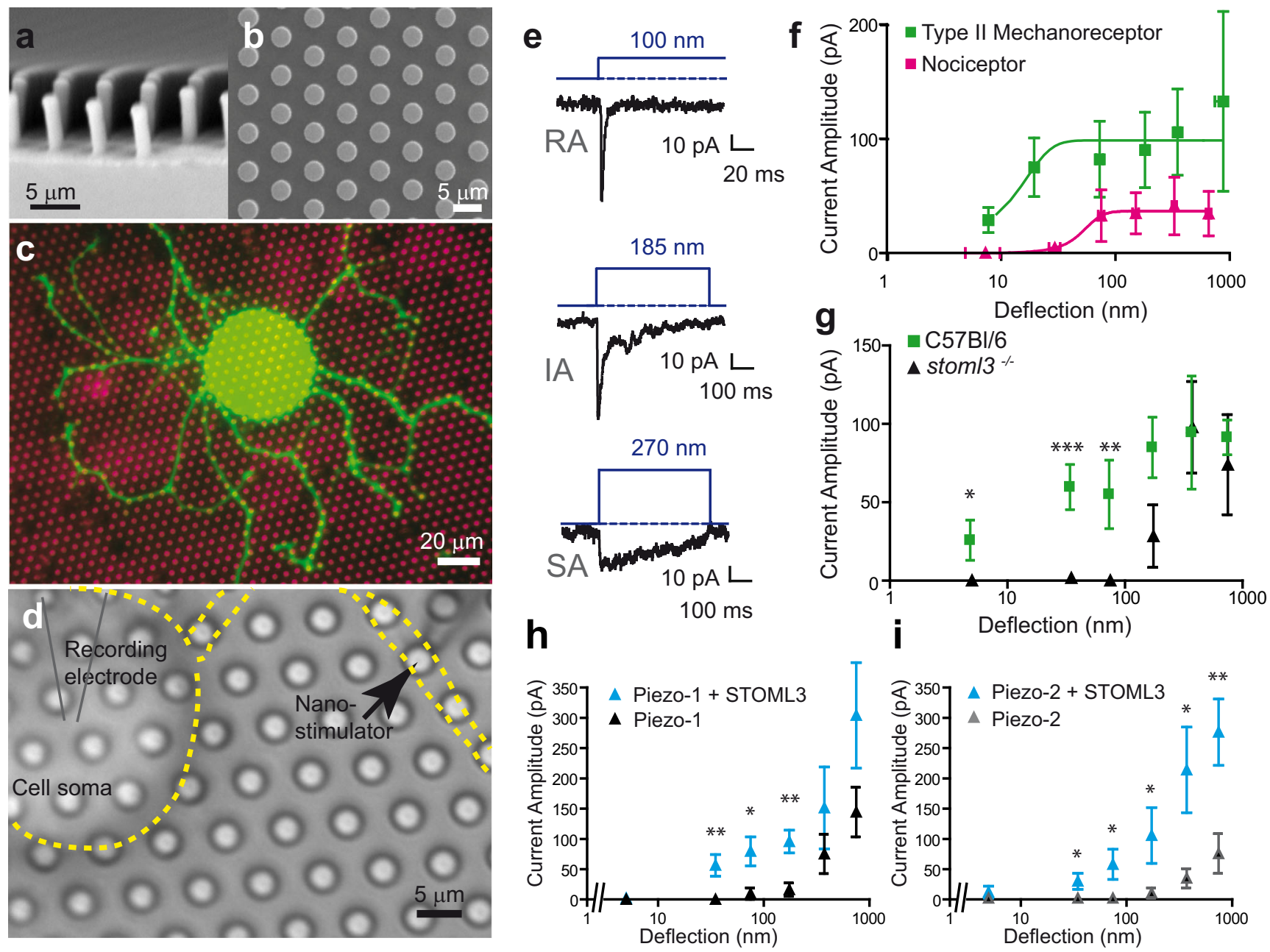

Fig. 2 Using elastomeric pillar arrays to quantitatively measure mechanotransduction at the membrane/matrix interface. a, b Scanning electron micrographs of elastomeric pillar arrays taken perpendicular (a) and parallel (b) to the elements of the array. $\mathbf{c}$ Pillar arrays can be coated with EHS-laminin (magenta), and sensory neurons acutely isolated from the mouse will attach to the array and extend neurites over the tops of the pili (green, overexpressed LifeAct-GFP). d Cells can be monitored using whole-cell patch clamp, and a glass nanostimulator can be used to deflect individual pillar elements directly underneath the neurite, bright field image, cell outlined in yellow, black arrow indicates individual pilus being deflected. e Sensory neurons respond to pillar deflection with rapidly adapting (RA), intermediate-adapting (IA) and slowly adapting

(SA) currents. f Stimulus-response curves indicate the higher sensitivity of mechanoreceptors ( $n=8$ cells) vs nociceptors $(n=13$ cells), note a Boltzmann fit of typeII mechanoreceptor data indicates that a stimulus of $13 \mathrm{~nm}$ is required for half-maximal activation of mechanically gated currents in these cells. $g$ The sensitivity of type II mechanoreceptors is dependent on the presence of STOML3; C57Bl/6, $n=8$ cells; stoml3-/-, $n=8$ cells. (h, i) In a heterologous system, HEK-293 cells, Piezo1- (h, black triangles, $n=9$ cells) and Piezo2- (i, grey triangles, $n=10$ cells) mediated currents are more sensitive when these channels are coexpressed with STOML3 (cyan triangles; Piezo1 + STOML3, $n=11$ cells; Piezo2 + STOML3, $n=9$ cells). Significance determined using a Student's $t$ test, ${ }^{*} p<0.05,{ }^{* *} p<0.01,{ }^{* * *} p<0.001$. Data from [85]

plasma membrane-matrix interface, we could use whole-cell patch clamp to measure mechanosensitive currents directly activated by defined matrix deflections [85]. When applied to cultured sensory neurons, this method revealed that pillar deflection evoked RA, IA or SA currents in all cells. Importantly, the activation and inactivation kinetics of all three types of mechanosensitive currents were virtually identical to those found with neurite indentation [85]. This finding strongly suggests that the opening of channels measured after cell indentation is, at least in part, identical with those activated by matrix deflection. The pili method allows a highly defined part of membrane $\left(10 \mu \mathrm{m}^{2}\right.$ in area) to be interrogated with a defined stimuli; thus, for a single neuron, we could test multiple sites. We could conclude from such experiments that mechanosensitive currents with different inactivation kinetics were often present in the same neurons. What determines the inactivation kinetics of the mechanosensitive current? It is most often assumed that channel inactivation is an intrinsic property of the channel in question. Thus, currents that inactivate with dramatically different rates may represent the activation of different channel entities. However, since the molecular nature of the channel(s) that underlie fast 


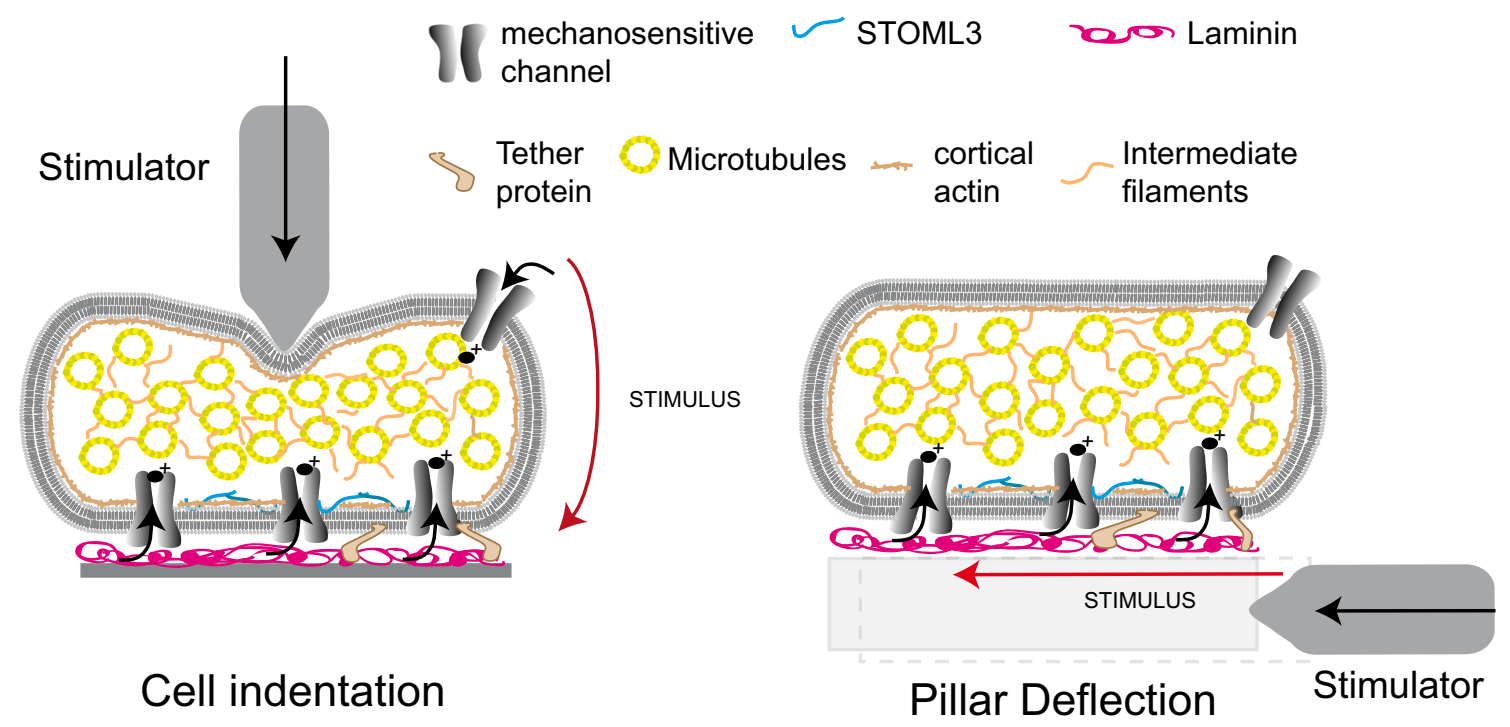

Fig. 3 Schematic representation of indentation vs pillar deflection. When a mechanical stimulus is applied by the indentation of the soma or neurite, the stimulus is propagated via the cell to the matrix-membrane interface.

mechanosensitive currents is unclear, there remains the possibility that mechanical elements that are part of the mechanotransduction complex govern the rate of channel inactivation. However, several groups have described differences in the pharmacological sensitivity or ion selectivity of SA, IA and RA currents [48, 62], e.g. selective sensitivity of the SA current to block the NMB-1 peptide [30], that do suggest that currents with different inactivation properties are mediated by distinct ion channel entities.

Using pillar arrays, we could, for the first time, make accurate measurements of the magnitude of the mechanical stimulus required for current activation. Irrespective of the type of current found in sensory neurons (RA, IA or SA), we noted that nociceptors always exhibited currents with high thresholds (mostly between 200 and 1,000 nm) whereas many mechanoreceptors exhibited extraordinarily low thresholds of $<50 \mathrm{~nm}$. Indeed, we obtained evidence for heterogeneity within the mechanoreceptor population with one group of neurons with a distinctive action potential configuration showing the highest sensitivity. Mechanoreceptors with narrow action potentials (APs) which we designated as type II cells showed half-maximal current activation with just $13 \mathrm{~nm}$ of pili deflection, a molecular scale deflection corresponding to the width of half a microtubule. Interestingly, these neurons showed APs that were very reminiscent of the most sensitive cutaneous mechanoreceptor, the D-hair receptor $[26,27,89$, 94], that forms lanceolate endings around most hair follicles in the hairy skin $[64,66,67]$. Even for neurons with higher threshold deflection-sensitive currents, the mechanical stimuli needed to evoke the current were often an order of magnitude lower than the size of the indentation stimuli needed to evoke similar currents in the same cells. The pillar array system has
In contrast, pillar deflection allows the application of fine, quantifiable stimuli directly to the membrane-matrix interface. Adapted from [85]

also proved valuable for the study of proteins that modulate the sensitivity of mechanosensitive channels like STOML3, a membrane protein that appears to be a functional orthologue of the MEC-2 protein in C. elegans [77, 83, 96].

The mechanosensitivity of the nematode body touch receptor and mouse sensory neurons is known to be dependent on the presence of stomatin-domain-containing protein, MEC-2 in the worm and STOML3 in the mouse $[49,83,96,98]$. Both MEC-2 and STOML3 are integral membrane proteins that insert like a hairpin into the plasma membrane leaving both $\mathrm{N}$ - and C-terminal peptides cytoplasmic [60]. In the absence of MEC-2, there is no detectable receptor potential in the body touch receptor neuron, and MEC-2 is a powerful positive regulator of the core mechanosensing channels MEC-4 and MEC-10 in these neurons. However, heterologously expressed MEC-4 and MEC-10 have not been described as being intrinsically mechanosensitive $[11,38]$. A high-resolution X-ray crystal structure of the mouse stomatin domain from stomatin has revealed a high degree of structural similarity between mammalian and bacterial stomatin domains [9]. However, structure-function studies as well as biochemical measurements have shown that the mammalian stomatin domain from stomatin forms a stable banana-shaped dimer via C-terminal interaction domain [9]. The dimerization mode of the stomatin domain in conjunction with the membrane anchoring could conceivably produce a scaffold that could influence the way that force reaches the channels associated with STOML3. The crystal packing of stomatin dimers also suggest higher-order interaction sites on the surface of the stomatin domain that may be functionally important [9]. In the absence of STOML3, many sensory neurons lose mechanosensitive currents upon indentation of the soma or 
neurites. We used pillar arrays to study mechanosensitive currents gated by matrix deflection in sensory neurons lacking STOML3. Surprisingly, we found that all sensory neurons possess a deflection-gated current in stoml $3^{-/-}$mice, but the thresholds for current deflection were dramatically elevated, up to five times larger than in wild type [85]. The effects of Stoml3 gene deletion were most prominent in the low-threshold type II neurons, but the absence of STOML3 also led to a significant elevation of deflection thresholds in nociceptor neurons with slowly inactivating currents. The activation speed of mechanosensitive currents as well as the mechanical latency was dramatically slowed in nociceptor neurons in the absence of STOML3. These data suggest that STOML3 plays a critical role in sensitizing mechanically gated ion channels to matrix deflection. The newly discovered Piezo2 protein has been implicated as being the molecular basis of non-selective RA-type mechanosensitive currents in sensory neurons [19]; we thus asked whether the sensitivity of Piezo channels to mechanical displacement could be regulated by STOML3. We found that STOML3 can powerfully tune the sensitivity of mechanically gated Piezo1 or Piezo2 channels. In mouse neuroblastoma cells, in which the Piezo1 protein was first identified, the knockdown of Stom 3 leads to a reduction in mechanosensitive currents measured using the pili technique [85]. Thus, the interaction between STOML3 and Piezo channels appears to be necessary to maintain the sensitivity of these channels to small matrix deflections. As such, we can conclude that the scaffold protein STOML3 is necessary to maintain the sensitivity of Piezo channels to physiologically relevant membrane displacement. Indeed the profound deficits observed in the sensitivity of native mechanosensitive currents in the absence of STOML3 suggest that in vivo Piezo2 channels are physiologically regulated by the STOML3 protein. The loss of mechanosensitive current sensitivity is sufficient to effectively silence many mechanoreceptors presumably because mechanical stimuli do not drive large enough receptor potentials to initiate action potentials in these neurons. The recent finding that Piezo2 is necessary for mechanotransduction currents in Merkel cells [71, 97] raises the question whether STOML3 also plays a role in the regulation of mechanosensitivity in this cell type. STOML3 represents, to our knowledge, the first example of a protein that regulates the sensitivity of an ion channel to mechanical stimuli. The structural requirements for the modulatory activity of STOML3 appear to be quite specific and reside largely in the stomatin-domain [85]. Stomatin has a stomatin domain that, in a STOML3 backbone, is not sufficient to regulate the sensitivity of Piezol channels [85], and the deletion of the stomatin gene in mice only leads to moderate changes in mechanoreceptor sensitivity [73]. However, loss of stomatin together with the Deg/ENaC channel ASIC3 leads to a complete loss of sensitivity in many thinly myelinated mechanonociceptors [91].

\section{Concluding remarks}

Many studies have shown that mechanosensing channels in sensory cells likely do not work alone, but rather within transmembrane complexes. In mammalian sensory neurons, we have shown that such complexes may anchor channels directly or indirectly to the extracellular matrix to facilitate the gating of mechanotransduction complexes in specialized sensory endings. In addition, it is clear that other proteins that can complex with and powerfully modulate mechanosensitive channels, like the Piezos, also play a critical role in regulating the sensitivity of the mechanotransducer. This regulation provides a molecular mechanism to explain the heterogeneity of mechanoreceptor sensitivity in different cutaneous receptors. The use of elastomeric pillar arrays allows the direct measurement of the activation of channels selectively at the membranematrix interface by mechanical deflection (Fig. 3). This will be an important tool in assessing mechanosensitive channels at membrane-matrix sites that are only partially accessible to recording with conventional techniques. A key issue question in the field is the question of whether ion channels need to be intrinsically sensitive to membrane stretch in order to serve as physiological mechanosensors. As pointed out in this review, there is no clear cut evidence that intrinsic mechanosensitivity is predictive or necessary for an ion channel protein to be a primary sensor of mechanical displacement or force.

Acknowledgments The author's work has been supported by grants from the Deutsche Forschungsgemeinschaft (collaborative research centre SFB 958 to KP and GRL), European Research Council (GRL) and the Alexander von Humboldt Foundation (MM).

Open Access This article is distributed under the terms of the Creative Commons Attribution License which permits any use, distribution, and reproduction in any medium, provided the original author(s) and the source are credited.

\section{References}

1. AbouAlaiwi WA, Takahashi M, Mell BR, Jones TJ, Ratnam S, Kolb RJ, Nauli SM (2009) Ciliary polycystin-2 is a mechanosensitive calcium channel involved in nitric oxide signaling cascades. Circ Res 104:860-869

2. Arnadóttir J, O'Hagan R, Chen Y, Goodman MB, Chalfie M (2011) The DEG/ENaC protein MEC-10 regulates the transduction channel complex in Caenorhabditis elegans touch receptor neurons. J Neurosci 31:12695-12704

3. Assad JA, Shepherd GM, Corey DP (1991) Tip-link integrity and mechanical transduction in vertebrate hair cells. Neuron 7:985-994

4. Banks RW, Cahusac PMB, Graca A, Kain N, Shenton F, Singh P, Njå A, Simon A, Watson S, Slater CR, Bewick GS (2013) Glutamatergic modulation of synaptic-like vesicle recycling in mechanosensory lanceolate nerve terminals of mammalian hair follicles. J Physiol (Lond) 591:2523-2540

5. Berrier C, Coulombe A, Houssin C, Ghazi A (1989) A patch-clamp study of ion channels of inner and outer membranes and of contact 
zones of E. coli, fused into giant liposomes. Pressure-activated channels are localized in the inner membrane. FEBS Lett 259: 27-32

6. Berrier C, Pozza A, De L de Lavalette A, Chardonnet S, Mesneau A, Jaxel C, le Maire M, Ghazi A (2013) The purified mechanosensitive channel trek-1 is directly sensitive to membrane tension. J Biol Chem 288:27307-27314

7. Besch SR, Suchyna T, Sachs F (2002) High-speed pressure clamp. Pflugers Arch 445:161-166

8. Beurg M, Fettiplace R, Nam J-H, Ricci AJ (2009) Localization of inner hair cell mechanotransducer channels using high-speed calcium imaging. Nat Neurosci 12:553-558

9. Brand J, Smith ESJ, Schwefel D, Lapatsina L, Poole K, Omerbašić D, Kozlenkov A, Behlke J, Lewin GR, Daumke O (2012) A stomatin dimer modulates the activity of acid-sensing ion channels. EMBO J 31:3635-3646

10. Brohawn SG, Su Z, MacKinnon R (2014) Mechanosensitivity is mediated directly by the lipid membrane in TRAAK and TREK1 K + channels. Proc Natl Acad Sci USA 111:3614-3619

11. Brown AL, Liao Z, Goodman MB (2008) MEC-2 and MEC-6 in the Caenorhabditis elegans sensory mechanotransduction complex: auxiliary subunits that enable channel activity. J Gen Physiol 131:605-616

12. Cesare P, McNaughton P (1996) A novel heat-activated current in nociceptive neurons and its sensitization by bradykinin. PNAS 93: 15435-15439

13. Chemin J, Patel AJ, Duprat F, Lauritzen I, Lazdunski M, Honoré E (2005) A phospholipid sensor controls mechanogating of the $\mathrm{K}+$ channel TREK-1. EMBO J 24:44-53

14. Chiang L-Y, Poole K, Oliveira BE, Duarte N, Sierra YAB, BrucknerTuderman L, Koch M, Hu J, Lewin GR (2011) Laminin-332 coordinates mechanotransduction and growth cone bifurcation in sensory neurons. Nat Neurosci 14:993-1000

15. Cho H, Koo JY, Kim S, Park SP, Yang Y, Oh U (2006) A novel mechanosensitive channel identified in sensory neurons. Eur J Neurosci 23:2543-2550

16. Cho H, Shin J, Shin CY, Lee S-Y, Oh U (2002) Mechanosensitive ion channels in cultured sensory neurons of neonatal rats. J Neurosci 22: $1238-1247$

17. Colquhoun D, Jonas P, Sakmann B (1992) Action of brief pulses of glutamate on AMPA/kainate receptors in patches from different neurones of rat hippocampal slices. J Physiol (Lond) 458: 261-287

18. Coste B, Crest M, Delmas P (2007) Pharmacological dissection and distribution of NaN/Nav1.9, T-type Ca2+ currents, and mechanically activated cation currents in different populations of DRG neurons. $\mathrm{J}$ Gen Physiol 129:57-77

19. Coste B, Mathur J, Schmidt M, Earley TJ, Ranade S, Petrus MJ, Dubin AE, Patapoutian A (2010) Piezo1 and Piezo2 are essential components of distinct mechanically activated cation channels. Science 330:55-60

20. Coste B, Xiao B, Santos JS, Syeda R, Grandl J, Spencer KS, Kim SE, Schmidt M, Mathur J, Dubin AE, Montal M, Patapoutian A (2012) Piezo proteins are pore-forming subunits of mechanically activated channels. Nature 483:176-181

21. Cunningham JT, Wachtel RE, Abboud FM (1997) Mechanical stimulation of neurites generates an inward current in putative aortic baroreceptor neurons in vitro. Brain Res 757:149-154

22. DeCaen PG, Delling M, Vien TN, Clapham DE (2013) Direct recording and molecular identification of the calcium channel of primary cilia. Nature 504:315-318

23. Delcour AH, Martinac B, Adler J, Kung C (1989) Modified reconstitution method used in patch-clamp studies of Escherichia coli ion channels. Biophys J 56:631-636

24. Delmas P, Hao J, Rodat-Despoix L (2011) Molecular mechanisms of mechanotransduction in mammalian sensory neurons. Nat Rev Neurosci 12:139-153
25. Di Castro A, Drew LJ, Wood JN, Cesare P (2006) Modulation of sensory neuron mechanotransduction by PKC- and nerve growth factor-dependent pathways. Proc Natl Acad Sci USA 103:4699-4704

26. Djouhri L, Bleazard L, Lawson SN (1998) Association of somatic action potential shape with sensory receptive properties in guinea-pig dorsal root ganglion neurones. J Physiol (Lond) 513(3):857-872

27. Djouhri L, Lawson SN (2001) Differences in the size of the somatic action potential overshoot between nociceptive and non-nociceptive dorsal root ganglion neurones in the guinea-pig. Neuroscience 108: 479-491

28. Domogatskaya A, Rodin S, Tryggvason K (2012) Functional diversity of laminins. Annu Rev Cell Dev Biol 28:523-553

29. Drew LJ, Rohrer DK, Price MP, Blaver KE, Cockayne DA, Cesare P, Wood JN (2004) Acid-sensing ion channels ASIC2 and ASIC3 do not contribute to mechanically activated currents in mammalian sensory neurones. J Physiol (Lond) 556:691-710

30. Drew LJ, Rugiero F, Cesare P, Gale JE, Abrahamsen B, Bowden S, Heinzmann S, Robinson M, Brust A, Colless B, Lewis RJ, Wood JN (2007) High-threshold mechanosensitive ion channels blocked by a novel conopeptide mediate pressure-evoked pain. PLoS ONE 2:e515

31. Drew LJ, Wood JN, Cesare P (2002) Distinct mechanosensitive properties of capsaicin-sensitive and -insensitive sensory neurons. J Neurosci 22:RC228

32. Du H, Gu G, William CM, Chalfie M (1996) Extracellular proteins needed for C. elegans mechanosensation. Neuron 16:183-194

33. Ernstrom GG, Chalfie M (2002) Genetics of sensory mechanotransduction. Annu Rev Genet 36:411-453

34. Fettiplace R, Hackney CM (2006) The sensory and motor roles of auditory hair cells. Nat Rev Neurosci 7:19-29

35. Franke C, Hatt H, Dudel J (1987) Liquid filament switch for ultra-fast exchanges of solutions at excised patches of synaptic membrane of crayfish muscle. Neurosci Lett 77:199-204

36. Frenzel H, Bohlender J, Pinsker K, Wohlleben B, Tank J, Lechner SG, Schiska D, Jaijo T, Rüschendorf F, Saar K, Jordan J, Millán JM, Gross M, Lewin GR (2012) A genetic basis for mechanosensory traits in humans. PLoS Biol 10, e1001318

37. Gillespie PG, Müller U (2009) Mechanotransduction by hair cells: models, molecules, and mechanisms. Cell 139:33-44

38. Goodman MB, Ernstrom GG, Chelur DS, O'Hagan R, Yao CA, Chalfie M (2002) MEC-2 regulates C. elegans $\mathrm{DEG} / \mathrm{ENaC}$ channels needed for mechanosensation. Nature 415:1039-1042

39. Gottlieb PA, Bae C, Sachs F (2012) Gating the mechanical channel Piezo1: a comparison between whole-cell and patch recording. Channels (Austin) 6:282-289

40. Gottlieb PA, Sachs F (2012) Piezo1: properties of a cation selective mechanical channel. Channels (Austin) 6:214-219

41. Guharay F, Sachs F (1984) Stretch-activated single ion channel currents in tissue-cultured embryonic chick skeletal muscle. J Physiol 352:685-701

42. Halata Z (1975) The mechanoreceptors of the mammalian skin ultrastructure and morphological classification. Adv Anat Embryol Cell Biol 50:3-77

43. Hamill OP, McBride DW (1992) Rapid adaptation of single mechanosensitive channels in Xenopus oocytes. Proc Natl Acad Sci U S A 89:7462-7466

44. Hao J, Delmas P (2010) Multiple desensitization mechanisms of mechanotransducer channels shape firing of mechanosensory neurons. J Neurosci 30:13384-13395

45. Heidenreich M, Lechner SG, Vardanyan V, Wetzel C, Cremers CW, De Leenheer EM, Aránguez G, Moreno-Pelayo MÁ, Jentsch TJ, Lewin GR (2012) KCNQ4 K (+) channels tune mechanoreceptors for normal touch sensation in mouse and man. Nat Neurosci 15:138-145

46. Honoré E, Patel AJ, Chemin J, Suchyna T, Sachs F (2006) Desensitization of mechano-gated K2P channels. PNAS 103: 6859-6864 
47. Hu J, Chiang L-Y, Koch M, Lewin GR (2010) Evidence for a protein tether involved in somatic touch. EMBO J 29:855-867

48. Hu J, Lewin GR (2006) Mechanosensitive currents in the neurites of cultured mouse sensory neurones. J Physiol (Lond) 577:815-828

49. Huang M, Gu G, Ferguson EL, Chalfie M (1995) A stomatin-like protein necessary for mechanosensation in C. elegans. Nature 378: 292-295

50. Iggo A, Muir AR (1969) The structure and function of a slowly adapting touch corpuscle in hairy skin. J Physiol (Lond) 200:763796

51. Ikeda R, Cha M, Ling J, Jia Z, Coyle D, Gu JG (2014) Merkel cells transduce and encode tactile stimuli to drive a $\beta$-afferent impulses. Cell 157:664-675

52. Kalkhof S, Witte K, Ihling CH, Müller MQ, Keller MV, Haehn S, Smyth N, Paulsson M, Sinz A (2010) A novel disulfide pattern in laminin-type epidermal growth factor-like (LE) modules of laminin $\beta 1$ and $\gamma 1$ chains. Biochemistry 49:8359-8366

53. Katz B (1950) Depolarization of sensory terminals and the initiation of impulses in the muscle spindle. J Physiol (Lond) 111:261-282

54. Kawahara K, Matsuzaki K (1992) Activation of calcium channel by shear-stress in cultured renal distal tubule cells. Biochem Biophys Res Commun 184:198-205

55. Kazmierczak P, Sakaguchi H, Tokita J, Wilson-Kubalek EM, Milligan RA, Müller U, Kachar B (2007) Cadherin 23 and protocadherin 15 interact to form tip-link filaments in sensory hair cells. Nature 449:87-91

56. Koschorke GM, Meyer RA, Campbell JN (1994) Cellular components necessary for mechanoelectrical transduction are conveyed to primary afferent terminals by fast axonal transport. Brain Res 641: 99-104

57. Kruger L, Perl ER, Sedivec MJ (1981) Fine structure of myelinated mechanical nociceptor endings in cat hairy skin. J Comp Neurol 198: $137-154$

58. Kruger L, Sampogna SL, Rodin BE, Clague J, Brecha N, Yeh Y (1985) Thin-fiber cutaneous innervation and its intraepidermal contribution studied by labeling methods and neurotoxin treatment in rats. Somatosens Res 2:335-356

59. Lane JW, McBride DW Jr, Hamill OP (1991) Amiloride block of the mechanosensitive cation channel in Xenopus oocytes. J Physiol (Lond) 441:347-366

60. Lapatsina L, Brand J, Poole K, Daumke O, Lewin GR (2012) Stomatin-domain proteins. Eur J Cell Biol 91:240-245

61. Lapatsina L, Jira JA, Smith ESJ, Poole K, Kozlenkov A, Bilbao D, Lewin GR, Heppenstall PA (2012) Regulation of ASIC channels by a stomatin/STOML3 complex located in a mobile vesicle pool in sensory neurons. Open Biol 2:120096

62. Lechner SG, Frenzel H, Wang R, Lewin GR (2009) Developmental waves of mechanosensitivity acquisition in sensory neuron subtypes during embryonic development. EMBO J 28:1479-1491

63. Lechner SG, Lewin GR (2009) Peripheral sensitisation of nociceptors via G-protein-dependent potentiation of mechanotransduction currents. J Physiol (Lond) 587:3493-3503

64. Lechner SG, Lewin GR (2013) Hairy sensation. Physiology (Bethesda) 28:142-150

65. Lewin GR, Moshourab R (2004) Mechanosensation and pain. J Neurobiol 61:30-44

66. Li L, Ginty DD (2014) The structure and organization of lanceolate mechanosensory complexes at mouse hair follicles. Elife 3:e01901

67. Li L, Rutlin M, Abraira VE, Cassidy C, Kus L, Gong S, Jankowski MP, Luo W, Heintz N, Koerber HR, Woodbury CJ, Ginty DD (2011) The functional organization of cutaneous low-threshold mechanosensory neurons. Cell 147:1615-1627

68. Loewenstein WR, Skalak R (1966) Mechanical transmission in a Pacinian corpuscle. An analysis and a theory. J Physiol (Lond) 182: 346-378
69. Maingret F, Fosset M, Lesage F, Lazdunski M, Honoré E (1999) TRAAK is a mammalian neuronal mechano-gated $\mathrm{K}+$ Channel. J Biol Chem 274:1381-1387

70. Maingret F, Patel AJ, Lesage F, Lazdunski M, Honoré E (2000) Lysophospholipids open the two-pore domain mechano-gated $\mathrm{K}(+)$ channels TREK-1 and TRAAK. J Biol Chem 275:10128-10133

71. Maksimovic S, Nakatani M, Baba Y, Nelson AM, Marshall KL, Wellnitz SA, Firozi P, Woo S-H, Ranade S, Patapoutian A, Lumpkin EA. (2014) Epidermal Merkel cells are mechanosensory cells that tune mammalian touch receptors. Nature

72. Martinac B, Buechner M, Delcour AH, Adler J, Kung C (1987) Pressure-sensitive ion channel in Escherichia coli. Proc Natl Acad Sci USA 84:2297-2301

73. Martinez-Salgado C, Benckendorff AG, Chiang L-Y, Wang R, Milenkovic N, Wetzel C, Hu J, Stucky CL, Parra MG, Mohandas $\mathrm{N}$, Lewin GR (2007) Stomatin and sensory neuron mechanotransduction. J Neurophysiol 98:3802-3808

74. McBride DW Jr, Hamill OP (1993) Pressure-clamp technique for measurement of the relaxation kinetics of mechanosensitive channels. Trends Neurosci 16:341-345

75. McCarter GC, Reichling DB, Levine JD (1999) Mechanical transduction by rat dorsal root ganglion neurons in vitro. Neurosci Lett 273:179-182

76. Methfessel C, Witzemann V, Takahashi T, Mishina M, Numa S, Sakmann B (1986) Patch clamp measurements on Xenopus laevis oocytes: currents through endogenous channels and implanted acetylcholine receptor and sodium channels. Pflugers Arch 407:577-588

77. Moshourab RA, Wetzel C, Martinez-Salgado C, Lewin GR (2013) Stomatin-domain protein interactions with acid-sensing ion channels modulate nociceptor mechanosensitivity. J Physiol (Lond) 591: $5555-5574$

78. Munger BL, Ide C (1988) The structure and function of cutaneous sensory receptors. Arch Histol Cytol 51:1-34

79. Munger BL, Pubols LM, Pubols BH (1971) The Merkel rete papilla - a slowly adapting sensory receptor in mammalian glabrous skin. Brain Res 29:47-61

80. Nauli SM, Jin X, AbouAlaiwi WA, El-Jouni W, Su X, Zhou J (2013) Non-motile primary cilia as fluid shear stress mechanosensors. Meth Enzymol 525:1-20

81. Noël J, Zimmermann K, Busserolles J, Deval E, Alloui A, Diochot S, Guy N, Borsotto M, Reeh P, Eschalier A, Lazdunski M (2009) The mechano-activated $\mathrm{K}+$ channels TRAAK and TREK-1 control both warm and cold perception. The EMBO Journal 28:1308-1318

82. O'Hagan R, Chalfie M (2006) Mechanosensation in Caenorhabditis elegans. Int Rev Neurobiol 69:169-203

83. O'Hagan R, Chalfie M, Goodman MB (2005) The MEC-4 DEG/ $\mathrm{ENaC}$ channel of Caenorhabditis elegans touch receptor neurons transduces mechanical signals. Nat Neurosci 8:43-50

84. Perozo E (2006) Gating prokaryotic mechanosensitive channels. Nat Rev Mol Cell Biol 7:109-119

85. Poole K, Herget R, Lapatsina L, Ngo H-D, Lewin GR (2014) Tuning Piezo ion channels to detect molecular-scale movements relevant for fine touch. Nat Commun 5:3520

86. Rugiero F, Drew LJ, Wood JN (2010) Kinetic properties of mechanically activated currents in spinal sensory neurons. J Physiol (Lond) 588:301-314

87. Ruknudin A, Song MJ, Sachs F (1991) The ultrastructure of patchclamped membranes: a study using high voltage electron microscopy. J Cell Biol 112:125-134

88. Sakmann B, Neher E (1984) Patch clamp techniques for studying ionic channels in excitable membranes. Annu Rev Physiol 46:455472

89. Shin J-B, Martinez-Salgado C, Heppenstall PA, Lewin GR (2003) A T-type calcium channel required for normal function of a mammalian mechanoreceptor. Nat Neurosci 6:724-730 
90. Siemens J, Lillo C, Dumont RA, Reynolds A, Williams DS, Gillespie PG, Müller U (2004) Cadherin 23 is a component of the tip link in hair-cell stereocilia. Nature 428:950-955

91. Söllner C, Rauch G-J, Siemens J, Geisler R, Schuster SC, Müller U, Nicolson T (2004) Tübingen 2000 Screen Consortium. Mutations in cadherin 23 affect tip links in zebrafish sensory hair cells. Nature 428: 955-959

92. Suchyna TM, Markin VS, Sachs F (2009) Biophysics and structure of the patch and the gigaseal. Biophys J 97:738-747

93. Sukharev SI, Blount P, Martinac B, Blattner FR, Kung C (1994) A large-conductance mechanosensitive channel in E. coli encoded by mscL alone. Nature 368:265-268

94. Wang R, Lewin GR (2011) The Cav3.2 T-type calcium channel regulates temporal coding in mouse mechanoreceptors. J Physiol (Lond) 589:2229-2243

95. Wende H, Lechner SG, Cheret C, Bourane S, Kolanczyk ME, Pattyn A, Reuter K, Munier FL, Carroll P, Lewin GR, Birchmeier C (2012)
The transcription factor c-Maf controls touch receptor development and function. Science 335:1373-1376

96. Wetzel C, Hu J, Riethmacher D, Benckendorff A, Harder L, Eilers A, Moshourab R, Kozlenkov A, Labuz D, Caspani O, Erdmann B, Machelska H, Heppenstall PA, Lewin GR (2007) A stomatin-domain protein essential for touch sensation in the mouse. Nature 445:206209

97. Woo S-H, Ranade S, Weyer AD, Dubin AE, Baba Y, Qiu Z, Petrus M, Miyamoto T, Reddy K, Lumpkin EA, Stucky CL, Patapoutian A. (2014) Piezo2 is required for Merkel-cell mechanotransduction. Nature

98. Zhang S, Arnadottir J, Keller C, Caldwell GA, Yao CA, Chalfie M (2004) MEC-2 is recruited to the putative mechanosensory complex in C. elegans touch receptor neurons through its stomatin-like domain. Curr Biol 14:1888-1896

99. Zhao Y, Yamoah EN, Gillespie PG (1996) Regeneration of broken tip links and restoration of mechanical transduction in hair cells. Proc Natl Acad Sci USA 93:15469-15474 